\title{
8. Synthesis of Side-chain Liquid-crystalline Polymers with Narrow Molecular Weight Distribution from Mesogenic Methacrylates Using Aluminum Porphyrin Complex
}

\author{
By Toshiyuki KodaIRA, *) Teruhiko TAnAKA, and Kazumi Mori \\ Department of Materials Science and Engineering, Faculty of Engineering, \\ Fukui University, Fukui 910
}

(Communicated by Seizo Okamura, M. J. A., March 14, 1994)

\begin{abstract}
Synthesis of side-chain liquid-crystalline polymers with narrow molecular weight distribution and controlled molecular weight from mesogenic methacrylates (MEM) with cyano and/or ester groups in their mesogen was achieved through their photopolymerization using $(5,10,15,20$-tetraphenylporphinato)aluminum methyl (MTPP) as a photosensitizer. The poly(MEM) obtained using MTPP have slightly higher contents of syndiotactic triads and lower contents of isotactic and heterotactic triads than those obtained with a radical initiator. Further, it was found that the tacticities of poly(MEM) are not much different from those of poly(methyl methacrylate) for both the polymerization systems, i.e., polymerizations with MTPP and the radical initiator. Copolymerizations of MEM initiated with MTPP and the radical initiator yielded copolymers with same compositions as those of monomer mixture in feed. Possibility for the control of molecular weight and its distribution of the copolymers obtained using MTPP has been shown. These results opened the way for the synthesis of block copolymers with liquid-crystalline polymeric chain as one component which are considered to form liquid crystals with unique properties, e.g., dimensional stability.
\end{abstract}

Key words: Mesogenic methacrylate; liquid-crystalline polymer; living polymerization; monodisperse polymer; aluminum porphyrin complex; tacticity; copolymerization.

1. Introduction. One of the characteristic features of macromolecular compounds is that they don't have defined molecular weight in a sense of low molecular weight compounds except for some of naturally occurring polymers. Polymers with narrow molecular weight distribution (MWD) and defined molecular weight are desirable when they are used as materials, since these factors influence occasionally properties of the polymers. For this reason control of molecular weight and its distribution is one of the most important targets of polymer chemists. This is not the exception in the synthesis of liquid-crystalline (LC) polymers. LC polymers are classified mainly into two groups, i.e., main-chain and side-chain LC polymers. The former have been studied extensively with an aim to get polymers with high strength and high modulus. The purpose of the investigation on the latter has been to get new specialty polymers which have unique properties derived from macromolecules in addition to those of low molecular weight liquid crystals. Some of the main-chain LC polymers are now available as industrial materials. However, almost all of these LC polymers are polydisperse. This is because polydisperse polymers are inevitably formed from the polycondensation or the polyaddition which is the polymerization method for the synthesis of main-chain LC polymers and from the radical polymerization which is the main procedure for the synthesis of side-chain LC polymers. ${ }^{1)}$ However, recent developments in living polymerization have enlarged the possibility to obtain monodisperse polymers. ${ }^{2-6)}$ Comparison of properties of LC polymers with narrow

*) Correspondence to: T. Kodaira. 
MWD with those with broad MWD is one of interesting problems to be investigated. In fact, several side-chain LC polymers with narrow MWD have been synthesized ${ }^{7)}$ and it was found that some of them shows different thermal properties from those with broader MWD. ${ }^{8), 9)}$

Living polymerization of mesogenic monomers yields not only LC polymers with narrow MWD but also block copolymers with LC polymeric chains as one component. Such block copolymers are considered to form liquid crystals with unique properties, such as dimensional stability. In view of these considerations we have carried out photopolymerization of 6-[4-\{4-(butoxyphenoxy)carbonyl $\}$ phenoxy]hexyl methacrylate (MOB) using (5,10,15,20-tetraphenylporphinato)aluminum methyl (MTPP) as a photo-sensitizer. This is because the photo-polymerization of methyl methacrylate (MMA) using MTPP as a photo-sensitizer has been reported to proceed through living mechanism. ${ }^{6}$ The results obtained showed that this polymerization system allows the living polymerization of MOB. ${ }^{10)}$ The synthesis of poly(MMA)-b-poly(MOB) was also successfully achieved by polymerizing MOB from the living propagating chain end of poly(MMA) obtained using MTPP. ${ }^{11)}$ Differential scanning calorimetric analyses of the block copolymers obtained have suggested that they have structure with micro phase separation. ${ }^{11}$ )

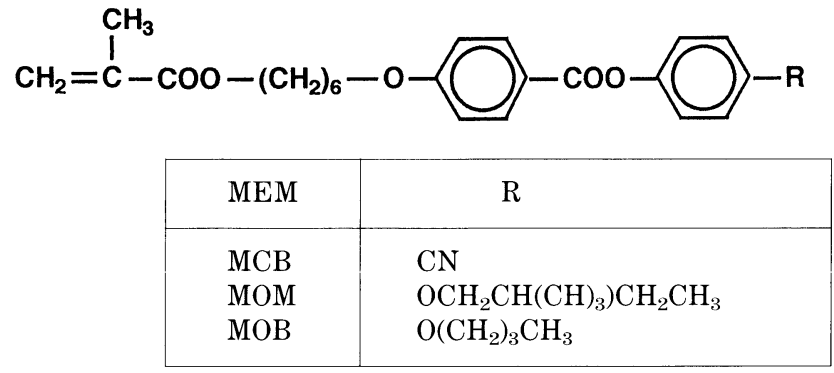

MEM

Methacrylic acid esters with mesogenic group (MEM) can be polymerized through living mechanism by "group-transfer polymerization" but living polymerization could not be attained in the monomers containing ester group in their mesogen by this polymerization method. ${ }^{12), 13)}$ It has been recently reported that anionic polymerization allows the living polymerization of a mesogenic methacrylate with ester group in its mesogen, ${ }^{14)}$ though this polymerization method has long been failed to achieve living polymerization of mesogenic methacrylates. However, the number and variety of mesogenic methacrylates which have been utilized for the living polymerization are limited. Based on these facts, the applicability of MTPP to the living polymerization of mesogenic methacrylates with various functional groups such as cyano, ester, or optically active group, which have been frequently introduced in mesogenic group, was examined in this work.

Further, copolymerization behavior of MEM and structural analyses of the polymers obtained were investigated to get comprehensive understanding on the polymerization behavior of MEM with MTPP.

2. Experimental. Materials. 6-[4-\{4-(Cyanophenoxy)carbonyl $\}$ phenoxy]hexyl methacrylate (MCB), ${ }^{15)}$ 6-[4-\{4-(d-2-Methylbutoxy)phenoxy)carbonyl $\}$ phenoxy]hexyl methacrylate (MOM), ${ }^{16)}$ and 6-[4-\{4-(Butoxyphenoxy)carbonyl $\}$ phenoxy]hexyl methacrylate $(\mathrm{MOB})^{16)}$ was synthesized according to the procedure reported or based on the synthetic methods described for similar compounds. MMA and solvents were purified by the usual methods. Trimethyl aluminum solution in hexane (Tokyo Kasei Co., Ltd.) and 5,10,15,20- 
tetraphenyl-21H, $23 \mathrm{H}$-porphyrin (Contains $<0.1 \%$ corresponding chlorin. Aldrich Chemicals Co., Ltd.) were used as received. Commercial 2,2'-azoisobutyronitrile (AIBN) was recrystallized from ethyl alcohol.

Polymerization. Preparation of MTPP and polymerization procedure initiated with MTPP are essentially the same as those reported for MMA. ${ }^{17)}$ In the case where polymerization was carried out for a longer period, the polymerization mixtures were sealed off after several freeze-pump-thaw cycles. Photo-irradiation was carried out by using a $2 \mathrm{kw}$ Xenon arc lamp from a distance of $25 \mathrm{~cm}$ through Toshiba V-Y 46 color glass filter at room temperature. After photo-irradiation for given time, an excess methyl alcohol was added, and the volatile materials were removed under reduced pressure. The solid residue obtained was dissolved in methylene dichloride and precipitated into methyl alcohol. Radical polymerization was carried out in benzene solution. Given amounts of monomer, solvent, and AIBN were placed in glass ampoules, which were then subjected to several freeze-pump-thaw cycles and sealed. After polymerization in a constanttemperature bath, the polymers were isolated by pouring the polymerization system into methanol.

Copolymerization. Copolymerizations were carried out based on the same experimental procedures as those of homopolymerizations for both MTPP and AIBN initiated systems except for the fact that a pair of monomers was used.

Measurements. ${ }^{1} \mathrm{H}(270 \mathrm{MHz})$ nuclear magnetic resonance (NMR) spectra were obtained in $\mathrm{CDCl}_{3}$ with tetramethylsilane (TMS) as an internal standard using a JEOL GX-270 FT NMR spectrometer. Gel-permeation chromatography (GPC) was performed on a JASCO TRI ROTAR-II using THF as eluent. The column set consisted of Shodex KF-802.5, A-800P, and A-80M. A molecular weight calibration curve was obtained by using standard polystyrene.

3. Results and discussion. 3.1. Homopolymerization of MEM. The results of the polymerizations of MEM obtained under the application of MTPP is given in Table I together with those of their radical polymerizations. The results of MOB and MMA which have already been reported ${ }^{10)}$ are also given for comparison. In contrast to the broad MWD of the polymer obtained with AIBN, a narrow MWD of poly(MEM) produced by MTPP can be recognized (ratio of weight average to number average molecular weight, $\mathrm{M}_{\mathrm{w}} / \mathrm{M}_{\mathrm{n}}=1.08 \sim 1.22$ ). Furthermore, the polymer's $\mathrm{M}_{\mathrm{n}}$ is in good agreement with the calculated value assuming that at the beginning all MTPP molecules form active species. These results suggest that the methacrylate with cyano group in addition to ester group in

Table I. Polymerization of MEM with MTPPa)

\begin{tabular}{|c|c|c|c|c|c|c|c|c|}
\hline \multirow{2}{*}{ No. } & \multirow{2}{*}{$\begin{array}{l}\text { Mono- } \\
\text { mer }\end{array}$} & \multirow{2}{*}{$\begin{array}{l}{[\mathrm{M}]_{0}} \\
\mathrm{mmol}\end{array}$} & \multirow{2}{*}{$\begin{array}{c}{[\mathrm{I}]_{0}} \\
\mathrm{~mol} \%\end{array}$} & \multirow{2}{*}{$\underset{\mathrm{h}}{\text { Time }}$} & \multicolumn{2}{|c|}{$\mathrm{M}_{\mathrm{n}} \cdot 10^{-3}$} & \multirow{2}{*}{$\mathrm{M}_{\mathrm{w}} / \mathrm{M}_{\mathrm{n}}$} & \multirow{2}{*}{$\begin{array}{c}\text { Conv. } \\
\%\end{array}$} \\
\hline & & & & & Obsd. & Calcd. & & \\
\hline 1 & MCB & 2.2 & 3.9 & 10 & 8.5 & 9.1 & 1.14 & 87 \\
\hline 2 & MOM & 2.2 & 3.9 & 10 & 9.5 & 10.9 & 1.22 & 94 \\
\hline $3^{\mathrm{b})}$ & MOB & 2.2 & 3.9 & 10 & 8.5 & 10.8 & 1.13 & 92 \\
\hline $4^{\mathrm{b})}$ & MMA & 9.4 & 0.9 & 4 & 10.2 & 10.1 & 1.17 & 92 \\
\hline $5^{\mathrm{c})}$ & $\mathrm{MCB}$ & 1.1 & 2.0 & 36 & 14.2 & - & 1.65 & 95 \\
\hline $6^{\mathrm{c})}$ & MOM & 1.1 & 2.0 & 36 & 110.0 & - & 3.25 & 58 \\
\hline $7^{\mathrm{b}), \mathrm{c})}$ & MOB & 1.1 & 2.0 & 36 & 44.0 & - & 2.94 & 86 \\
\hline
\end{tabular}

a) At room temperature using $6.5 \mathrm{ml}$ of $\mathrm{CH}_{2} \mathrm{Cl}_{2}$ as solvent.

b) Quoted from ref. 10 .

c) Radical polymerization at $60^{\circ} \mathrm{C}$ initiated with AIBN using $6 \mathrm{ml}$ of benzene as solvent. 
the mesogen, i.e., MCB, can be polymerized through living mechanism by using MTPP. It can be noticed that MOM has almost the same polymerization tendency as that of MOB. This might be due to the fact that 2-methylbutoxy group is too far from the reaction site to influence the polymerizability of MOM. Results of the polymerization of MMA indicates that these mesogenic methacrylates have considerably high polymerizability.

3.2 Tacticity of poly(MCB). ${ }^{1} \mathrm{H}$ NMR spectrum of poly(MCB) obtained using MTPP is illustrated in Fig. 1 for the region from 2.7 to 0.3 ppm. Absorptions at 1.27, 1.07, and $0.9 \mathrm{ppm}$ have been attributed to isotactic (I), heterotactic $(\mathrm{H})$, and syndiotactic (S) triads of C-methyl protons based on the results reported for poly(MMA). ${ }^{18)}$ Weak signal at $0.74 \mathrm{ppm}$ is considered to be due to methyl protons derived from methyl group attached to aluminum of MTPP, judging from the fact that the higher the content of MTPP in polymerization system, the stronger the peak intensity. The stereoregularities of poly $(\mathrm{MCB})$ determined based on these peak intensities are summarized in Table II along with those of poly(MMA) and polymers obtained using radical initiator. It can be seen that the polymers derived from MCB using MTPP have slightly higher contents of syndiotactic triads and lower contents of isotactic and heterotactic triads than those obtained by radical initiator. Further, it can be recognized that the tacticities of poly(MCB) are not much different from those of poly(MMA) for both the polymerization systems, i.e., polymerization with MTPP and AIBN. Polymers derived from other mesogenic methacrylates than MCB have absorption due to substituents in the areas where C-methyl protons are observed. This does not allow to determine the tacticities of these polymers. However, the fact that ${ }^{1} \mathrm{H}$ NMR spectra of the polymers derived from other MEM using MTPP and AIBN have almost similar pattern suggests that stereoregularities of these polymers are not much different from each other as in poly(MCB).

3.3. Copolymerizations of MCB with MOB. Copolymerization of MCB with MOB was undertaken using MTPP. The copolymer compositions were determined based on the

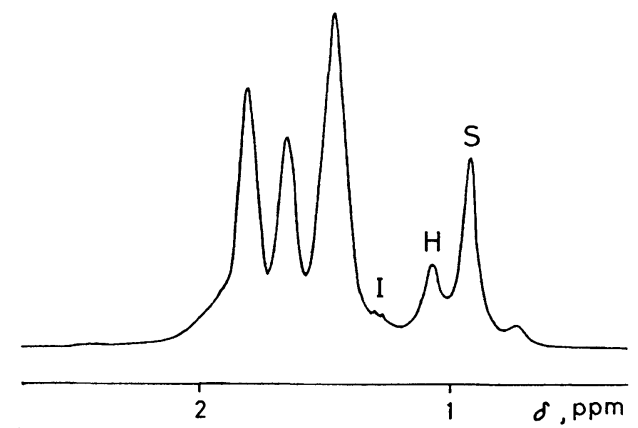

Fig. 1. ${ }^{1} \mathrm{H}$ NMR spectrum of poly(MCB) (No. 1 in Table II).

Table II. Tacticity of poly(MCB)

\begin{tabular}{|c|c|c|c|c|c|c|c|}
\hline \multirow{2}{*}{ No. } & \multirow{2}{*}{ Polymer } & \multirow{2}{*}{ Initiator } & \multirow{2}{*}{$\mathrm{M}_{\mathrm{n}} \cdot 10^{-3}$} & \multirow{2}{*}{$\mathrm{M}_{\mathrm{w}} / \mathrm{M}_{\mathrm{n}}$} & \multicolumn{3}{|c|}{ Tacticity, \% } \\
\hline & & & & & I & $\mathrm{H}$ & $\mathrm{S}$ \\
\hline 1 & Poly(MCB) & MTPP & 8.5 & 1.14 & 2.3 & 32.3 & 65.4 \\
\hline 2 & Poly(MCB) & AIBN & 14.2 & 1.65 & 5.4 & 36.2 & 58.4 \\
\hline 3 & Poly(MMA) & MTPP & 11.6 & 1.08 & 2.2 & 27.6 & 70.2 \\
\hline 4 & Poly(MMA) ${ }^{a)}$ & AIBN & 27.4 & 2.12 & 4.0 & 34.7 & 61.3 \\
\hline
\end{tabular}

a) Quoted from ref. 18 . 
peak intensities of characteristic absorptions which can be ascribed to the structural units derived from MCB and MOB and they are illustrated in Fig. 2 for the copolymers with conversion less than $10 \%$. The results obtained by using AIBN as an initiator were also shown for comparison. It can be seen that both initiator systems yield copolymers with same compositions as those of monomer mixture in feed. This can be understood by the fact that the structural difference between the two monomers exists at the position far from the reaction sites. Since copolymers with same composition were obtained in the copolymerizations with MTPP and AIBN, MWD of the copolymers were measured. The results obtained using MTPP are summarized in Table III. In the case where higher concentration of MTPP was used, copolymers with narrow MWD were obtained. Furthermore, the initiator efficiency was found to be almost quantitative, as can be seen from the comparison of molecular weight determined by GPC with the value calculated. However, the MWD is considerably broad and molecular weights obtained are extensively different from the values calculated in the case where concentration of MTPP is low. These results suggest that impurities present in LC monomer prevent living polymerization. Difficulty in getting highly pure LC monomers as compared with MMA can be understood considering the fact that the former is obtained in small amounts after multistep synthesis. The results of the radical copolymerizations of MCB with MOB are given in Table IV. Formation of copolymers with broader MWD is recognized, which is usual case for radical polymerization.

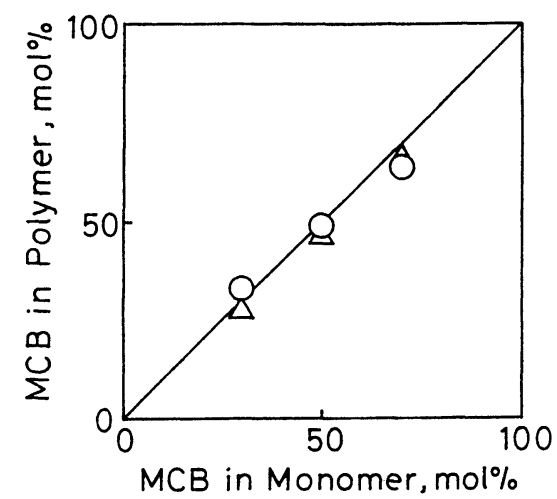

Fig. 2. Copolymer composition of poly(MCB-co-MOB). (O), MTPP; $(\triangle)$, AIBN.

Table III. Copolymerization of MCB and MOB with MTPP

\begin{tabular}{|c|c|c|c|c|c|c|c|c|}
\hline No. & {$[\mathrm{MCB}]_{\mathrm{M}}{ }^{\mathrm{a})}$} & $\begin{array}{c}{[\mathrm{I}]_{0}} \\
\mathrm{~mol} \%\end{array}$ & $\underset{\mathrm{h}}{\mathrm{Time}}$ & $\begin{array}{c}\mathrm{M}_{\mathrm{n}} \\
\text { Obsd. }\end{array}$ & $\begin{array}{l}0^{-3} \\
\text { Calcd. }\end{array}$ & $\mathrm{M}_{\mathrm{w}} / \mathrm{M}_{\mathrm{n}}$ & $\begin{array}{c}\text { Conv. } \\
\%\end{array}$ & {$[\mathrm{MCB}]_{\mathrm{p}}^{\mathrm{b})}$} \\
\hline 1 & 0.70 & 0.98 & 1 & 7.7 & 3.0 & 3.84 & 7 & 0.64 \\
\hline 2 & 0.70 & 3.90 & 1 & 4.0 & 3.8 & 1.13 & 35 & 0.67 \\
\hline 3 & 0.50 & 0.98 & 1 & 17.0 & 5.6 & 2.96 & 13 & 0.49 \\
\hline 4 & 0.50 & 3.90 & 2 & 5.9 & 6.0 & 1.12 & 55 & 0.50 \\
\hline 5 & 0.30 & 0.98 & 1 & 11.0 & 4.0 & 2.83 & 9 & 0.33 \\
\hline 6 & 0.30 & 3.90 & 2 & 5.1 & 5.6 & 1.21 & 50 & 0.29 \\
\hline
\end{tabular}

a) $\mathrm{MCB}$ in monomer mixture in feed, mole fraction.

b) $\mathrm{MCB}$ in copolymer, mole fraction. 
Table IV. Copolymerization of MCB and MOB with AIBN

\begin{tabular}{ccccccrc}
\hline No. & {$[\mathrm{MCB}]_{\mathrm{M}}{ }^{\mathrm{a})}$} & $\begin{array}{c}{[\mathrm{I}]_{0}} \\
\mathrm{~mol} \%\end{array}$ & $\begin{array}{c}\text { Time } \\
\mathrm{h}\end{array}$ & $\mathrm{M}_{\mathrm{n}} \cdot 10^{-4}$ & $\mathrm{M}_{\mathrm{w}} / \mathrm{M}_{\mathrm{n}}$ & $\begin{array}{c}\text { Conv. } \\
\%\end{array}$ & {$[\mathrm{MCB}]_{\mathrm{p}}{ }^{\mathrm{b})}$} \\
\hline 1 & 0.70 & 0.51 & 2 & 4.2 & 1.37 & 5 & 0.67 \\
2 & 0.70 & 0.51 & 20 & 3.5 & 1.46 & 44 & 0.69 \\
3 & 0.50 & 0.51 & 2 & 6.6 & 2.14 & 6 & 0.47 \\
4 & 0.50 & 2.00 & 1 & 3.6 & 2.37 & 37 & 0.45 \\
5 & 0.50 & 2.00 & 10 & 4.2 & 2.70 & 79 & 0.47 \\
6 & 0.30 & 0.51 & 2 & 3.2 & 2.12 & 13 & 0.28 \\
7 & 0.30 & 0.51 & 20 & 6.6 & 2.42 & 70 & 0.29 \\
\hline
\end{tabular}

a) $\mathrm{MCB}$ in monomer mixture in feed, mole fraction.

b) MCB in copolymer, mole fraction.

4. Conclusion. The conclusions drawn are summarized below.

1. Synthesis of side-chain LC polymers with narrow MWD was achieved through the polymerization of MEM with cyano and ester groups in their mesogen using MTPP. The way for the synthesis of block copolymers with LC polymeric chain as one component has been opened.

2. Poly(MCB) obtained using MTPP has slightly higher contents of syndiotactic triads and lower contents of isotactic and heterotactic triads than that obtained by radical initiator. Further, the tacticities of poly $(\mathrm{MCB})$ are not much different from those of poly(MMA).

3. Copolymerization of MEM yielded copolymers with same composition as that of monomer mixture in feed. Possibility for the control of molecular weight and its distribution in the copolymerization of MEM has been shown.

Properties of the polymers obtained should be studied in near future.

\section{References}

1) K. Iimura, T. Asada, and A. Abe (ed.): Ekisho Kobunshi (Liquid Crystalline Polymers). Shiguma Publishing Co., Ltd., Tokyo (1988).

2) T. Higahimura, S. Aoshima, and M. Sawamoto: Makromol. Chem. Macromol. Symp, 13/14, 457 (1988).

3) Y. Doi and T. Keii: Adv. Polym. Sci., 73/74, 201 (1986).

4) K. Hatada et al.: Polym. J., 18, 1037 (1986).

5) O. W. Webster et al.: J. Am. Chem. Soc., 105, 5706 (1983).

6) S. Inoue et al.: Makromol. Chem., Macromol. Symp., 32, 255 (1990).

7) T. Kodaira: Kobunshi Kako (Polym. Applications), 42, 233, (1993).

8) T. Sagane and R. W. Lenz: Polym. J., 20, 923 (1988).

9) — : Macromolecules, 22, 3763 (1989).

10) T. Kodaira and K. Mori: Makromol. Chem., Rapid Commun., 11, 645 (1990).

11) —-: Makromol. Chem., 193, 1331 (1992)

12) V. Percek, D. Tomazos, and C. Pugh: Macromolecules, 22, 3259 (1989).

13) M. Heft and J. Springer: Makromol. Chem., Rapid Commun., 11, 397 (1990).

14) R. Bohnert, H. Finkelmann, and P. Lutz: ibid., 14, 139 (1993).

15) C. Noel et al.: Makromol. Chem., Macromol. Symp., 24, 283 (1989).

16) R. Zentel and H. Ringsdorf: Makromol. Chem., Rapid Commun., 5, 393 (1984).

17) M. Kuroki, T. Aida, and S. Inoue: J. Am. Chem. Soc., 109, 4737 (1987).

18) R. Chujo: Makromol. Chem., Macromol. Symp., 34, 59 (1990). 